\title{
Flora das cangas da Serra dos Carajás, Pará, Brasil: Frullaniaceae
}

Flora of the canga of the Serra dos Carajás, Pará, Brazil: Frullaniaceae

\author{
Eliene Lima ${ }^{1,2}$, Fúvio Rubens Oliveira-da-Silva ${ }^{1,2} \&$ Anna Luiza Ilkiu-Borges ${ }^{1,3}$
}

\begin{abstract}
Resumo
Apresenta-se um tratamento taxonômico para Frullaniaceae registrada nas áreas de cangas da Serra dos Carajás, no estado do Pará, com descrições, ilustrações e comentários morfológicos das espécies Frullania ericoides, F. exilis, F. gibbosa e F. intumescens.

Palavras-chave: Brioflora, FLONA Carajás, hepáticas, taxonomia.

Abstract

A taxonomic treatment for Frullaniaceae recorded in the areas of canga in Serra dos Carajás, Pará state, is presented, including descriptions, illustrations and morphologic comments on the species Frullania ericoides, $F$. exilis, $F$. gibbosa and $F$. intumescens
\end{abstract}

Key words: Bryoflora, FLONA Carajás, liverworts, taxonomy.

\section{Frullaniaceae}

Frullaniaceae Verdoorn é representada por três gêneros: Kaolakia Heinrichs et al. e Protofrullania Heinrichs, que são fósseis (Heinrichs et al. 2011, Heinrichs et al. 2017), e Frullania Raddi, com 573 espécies descritas distribuídas no globo (Söderström et al. 2016). No Brasil, está representada por 39 espécies (Costa \& Peralta 2015). A família é identificada pelas plantas de coloração enegrecida, avermelhada ou verde, com ramos prostrados, pinados, bipinados ou tripinados, filídios íncubos, conduplicados (divididos em um lobo dorsal e lóbulo ventral menor), lóbulos geralmente sacados (raro laminados), estilete presente entre o lóbulo e o caulídio, e perianto com 0-14 quilhas (Gradstein et al. 2001; Gradstein \& Costa 2003; Gradstein \& Ilkiu-Borges 2009; Gradstein \& Uribe-M 2011; Silva et al. 2016). Nas cangas da Serra dos Carajás foram identificadas quatro espécies de Frullania.

\section{Frullania Raddi}

Os membros deste gênero ocorrem geralmente sobre casca de árvores e rochas, ocasionalmente em ramos finos de árvores vivas e sobre folhas, em ambientes abertos, florestas não decíduas ou decíduas, cerrado, plantações, pastagens, savanas e barrancos à margem de estradas (Gradstein et al. 2001).

\section{Chave de identificação das espécies de Frullania das áreas de canga da Serra dos Carajás}

1. Filídios esquarrosos quando úmidos. Lóbulos orbicular-galeados ................................................. 2

1'. Filídios nunca esquarrosos quando úmidos. Lóbulos cilíndricos, curto-cilíndricos a obovaladocilíndricos

2. Filídios frágeis. Anfigastro 1/3 bífido, 260-420 × 250-400 $\mu \mathrm{m}$, contíguos a sub-imbricados, base arredondada a arredondado-truncada. Estilete filiforme. Perianto com três quilhas, margens ciliadas a curto-laciniadas, superfície com protuberâncias, cílio ou lacínias espalhadas (raras nos espécimes de Carajás) 1.1. Frullania ericoides

\footnotetext{
'Museu Paraense Emílio Goeldi, Av. Magalhães Barata 376, São Braz, 66040-170, Belém, PA, Brasil.

${ }^{2}$ UFRA/MPEG, Campus do Museu Paraense Emílio Goeldi, Prog. Pós-graduação em Ciências Biológicas - Botânica Tropical, Av. Perimetral 1901, Terra Firme, 66077-830, Belém, PA, Brasil.

${ }^{3}$ Autor para correspondência: ilkiu-borges@museu-goeldi.br
} 
2'. Filídios firmes. Anfigastro 1/9-1/5 bífido, 425-525 × 400-750 $\mu \mathrm{m}$, densamente imbricados, base auriculada, gibosa. Estilete foliado-arredondado. Perianto com quatro quilhas, margens inteiras, superfície lisa 1.3. Frullania gibbosa 3. Lóbulos contíguos ao caulídio ............................................... 1.4. Frullania intumescens 3'. Lóbulos distantes do caulídio (distância $\geq$ largura do lóbulo) 1.2. Frullania exilis

1.1. Frullania ericoides (Nees) Mont., Ann. Sci. Nat., Bot., sér. 2, 12(1): 51, 1839.

Jungermannia ericoides Nees, Fl. bras. 1(1): 346, 1833.

Fig. 1a-i

Plantas dióicas, verdes a marromavermelhadas, 1-1,25 $\mathrm{mm}$ de largura, prostradas, fracamente aderida ao substrato, $1-3$ pinados. Filídios frágeis, suborbiculares, 670-750 × 470-570 $\mu \mathrm{m}$, plano, convolutos quando secos e esquarrosos quando úmidos, base dorsal auriculada (ultrapassando o caulídio), ápice arredondado, margem inteira. Células medianas isodiamétricas, 20-28 $\mu \mathrm{m}$, trigônios inflados, 2-4 espessamentos intercelulares. Lóbulos contíguos ao caulídio, orbicular-galeados, 270-400 × 250-350 $\mu \mathrm{m}$, estreitamente aderidos ao lobo (porção laminada ausente), tão longos quanto largos, lóbulos laminares pouco frequentes. Estilete filiforme, 3-6 células comprimento, 1 de largura. Anfigastros 1/3 bífidos, 2-4 × largura do caulídio, obovalados a suborbicular, 260-420 × 250-400 $\mu \mathrm{m}$, contíguos a sub-imbricados, base arredondada a arredondadotruncada (nunca auriculada), margens inteiras ou com 1 dente nas laterais, planas. Brácteas e bractéolas do ginoécio com margens inteiras. Periantos obovalados, 1200-1600 × 800-900 $\mu \mathrm{m}$, 3 quilhas, margens ciliadas a curto-laciniadas, superfície com poucas protuberâncias, cílios ou lacínias espalhadas, rostro curto, 40-100 $\mu \mathrm{m}$ comprimento.

Material selecionado: Canaã dos Carajás, Serra Sul, Serra do Tarzan, $6^{\circ} 19^{\prime} 49^{\prime \prime} \mathrm{S}, 50^{\circ} 07^{\prime} 53,8$ 'W, $747 \mathrm{~m}$, 1.IX.2015, A.L. Ilkiu-Borges et al. 3678 (MG).

Frullania ericoides é diagnosticada pelos filídios esquarrosos quando úmidos, lóbulos orbicular-galeados e perianto com 3 quilhas com margens ciliadas a curto-laciniadas com poucas protuberâncias, cílios ou lacínias espalhadas entre as quilhas. A superfície do perianto de $F$. ericoides é geralmente coberta por tubérculos ou apêndices folhosos, como escamas (Gradstein \& Ilkiu-Borges 2009; Schuster 1992; Vanden Berghen 1976; Wigginton 2004). Todavia, nos espécimes da Canga de Carajás, a superfície do perianto raramente apresenta essas estruturas espalhadas, sendo geralmente lisa entre as quilhas.
É uma espécie xerófita, corticícola ou rupícola que ocorre em florestas abertas, restingas, manguezais, plantações e parques, de 200 a 1300 m de altitude (Gradstein \& Costa 2003; Gradstein $\&$ Ilkiu-Borges 2009). Nas Serra dos Carajás, essa espécie foi coletada sobre galho de árvore viva em mata baixa sobre canga.

Pantropical. No Brasil: AC, AL, AM, BA, CE, DF, ES, GO, MG, MS, PA, PA, PE, RJ, RS, SC. SE e SP. Serra dos Carajás: Serra Sul: Serra do Tarzan.

1.2. Frullania exilis Taylor, London Jour. of Bot. 405. $1846 . \quad$ Figs. 2a-i; 3a-g Plantas autóicas, marrom-avermelhadas, 0,6-1,2 $\mathrm{mm}$ de largura, prostradas, com ramos ascendentes, 1-2(-3) pinados. Hemi-filídio bífido (primeiro apêndice do ramo). Filídios firmes, ovalados, 500-650 × 400-580 $\mu \mathrm{m}$, côncavo, base dorsal reta a arredondada (nunca auriculada), ápice arredondado a apiculado, margem inteira. Células medianas isodiamétricas, 15-45 $\mu \mathrm{m}$, trigônios radiados a inflados, às vezes confluentes, 0-1 espessamento intercelular, grupo de células basais similares a ocelos presente. Lóbulos distantes do caulídio (distância $\geq$ largura do lóbulo), paralelos a subparalelos ao caulídio, cilíndricos, 165-250 × 75-100 $\mu \mathrm{m}, 2-2,5 \times$ mais longos que largos, com uma incisão no lado adaxial alcançando $1 / 3-1 / 2$ do lóbulo, geralmente com uma célula de cor mais avermelhada e intensa (similar a um ocelo) no final da incisão, sempre com uma célula grande e de cor avermelhada mais intensa (similar a um ocelo) na junção do lóbulo com estilete, lóbulos laminares frequentes. Estilete lanceolado a filiforme (2-4 células enfileiradas) com base de $2-5$ células. Anfigastros 1/3-1/2 bífidos, 1,5-3× largura do caulídio, ovalados a suborbiculares, 230-310 $\times$ 140-250 $\mu \mathrm{m}$, distantes a sub-imbricados, base cuneada a arredondada, margens inteiras, planas. Brácteas e bractéolas do ginoécio com margens inteiras a fortemente serreadas. Perianto obovado, 1000-1900 × 600-850 $\mu \mathrm{m}, 3$ quilhas, margens inteiras, superfície lisa, rostro curto, 90-100 $\mu \mathrm{m}$ comprimento. 


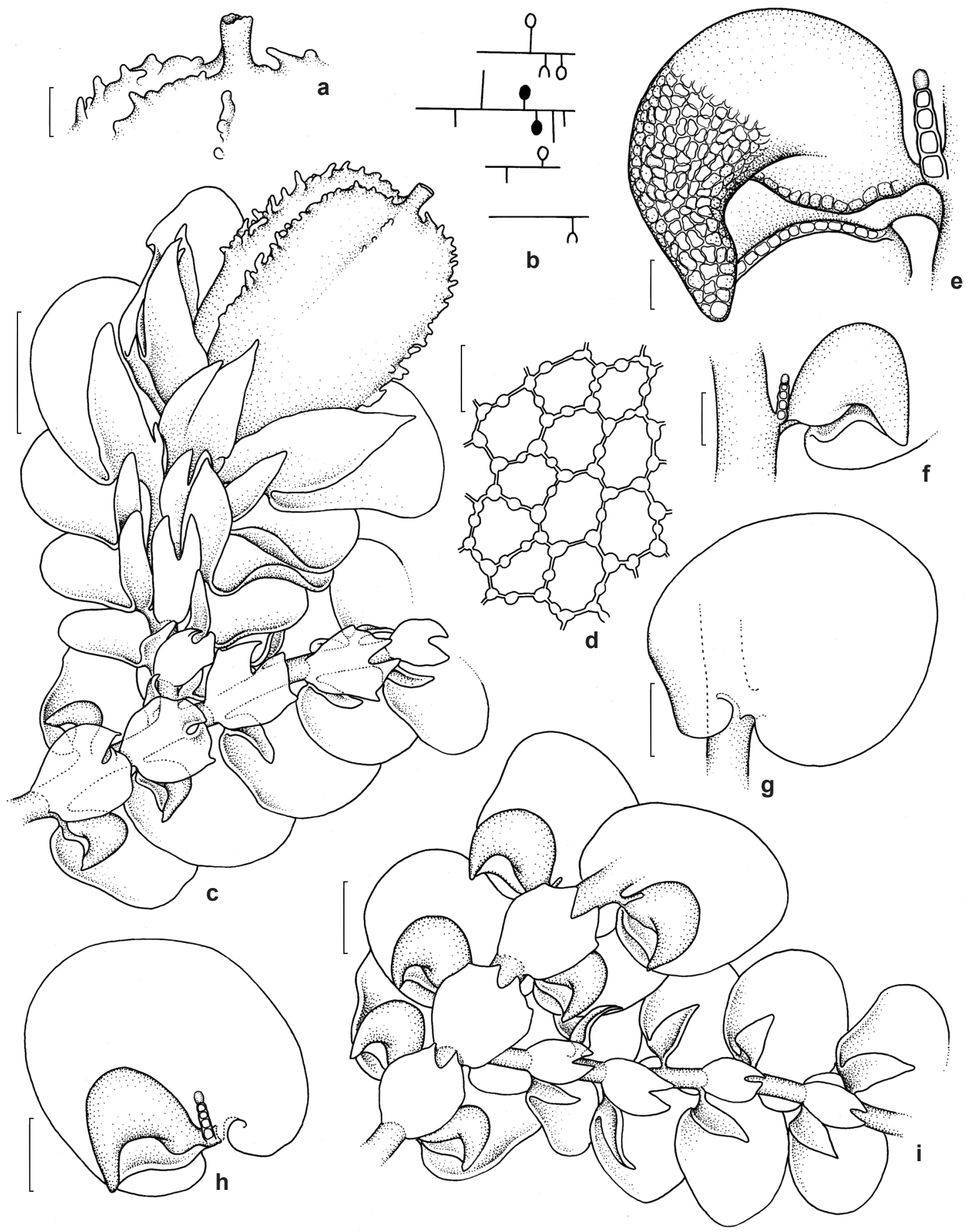

Figura 1 -a-i. Frullania ericoides - a. rostro do perianto; b. esquema de hábitos (esfera cheia= androécio, esfera vazada= ginoécio com perianto, $\mathrm{U}=$ ginoécio); c. hábito com perianto; d. células medianas; e-f. lóbulos com estilete; g. filídio em vista dorsal; h. filídio; i. hábito. Barras: $\mathrm{a}, \mathrm{f}=100 \mu \mathrm{m} ; \mathrm{c}=500 \mu \mathrm{m} ; \mathrm{d}=25 \mu \mathrm{m} ; \mathrm{e}=50 \mu \mathrm{m} ; \mathrm{g}, \mathrm{h}=200 \mu \mathrm{m} ; \mathrm{i}=250 \mu \mathrm{m}$. Figure 1 - a-i. Frullania ericoides - a. perianth beak; b. habit scheme (dot= androecia, open dot= gynoecia with perianth, $U=$ gynoecia); c. habit with perianth; d. median cells; e-f. lobules with stile; g. leaf in dorsal view; h. leaf; i. habit. Bars: a, $\mathrm{f}=100 \mu \mathrm{m} ; \mathrm{c}=500 \mu \mathrm{m}$; $\mathrm{d}=25 \mu \mathrm{m} ; \mathrm{e}=50 \mu \mathrm{m} ; \mathrm{g}, \mathrm{h}=200 \mu \mathrm{m} ; \mathrm{i}=250 \mu \mathrm{m}$. 


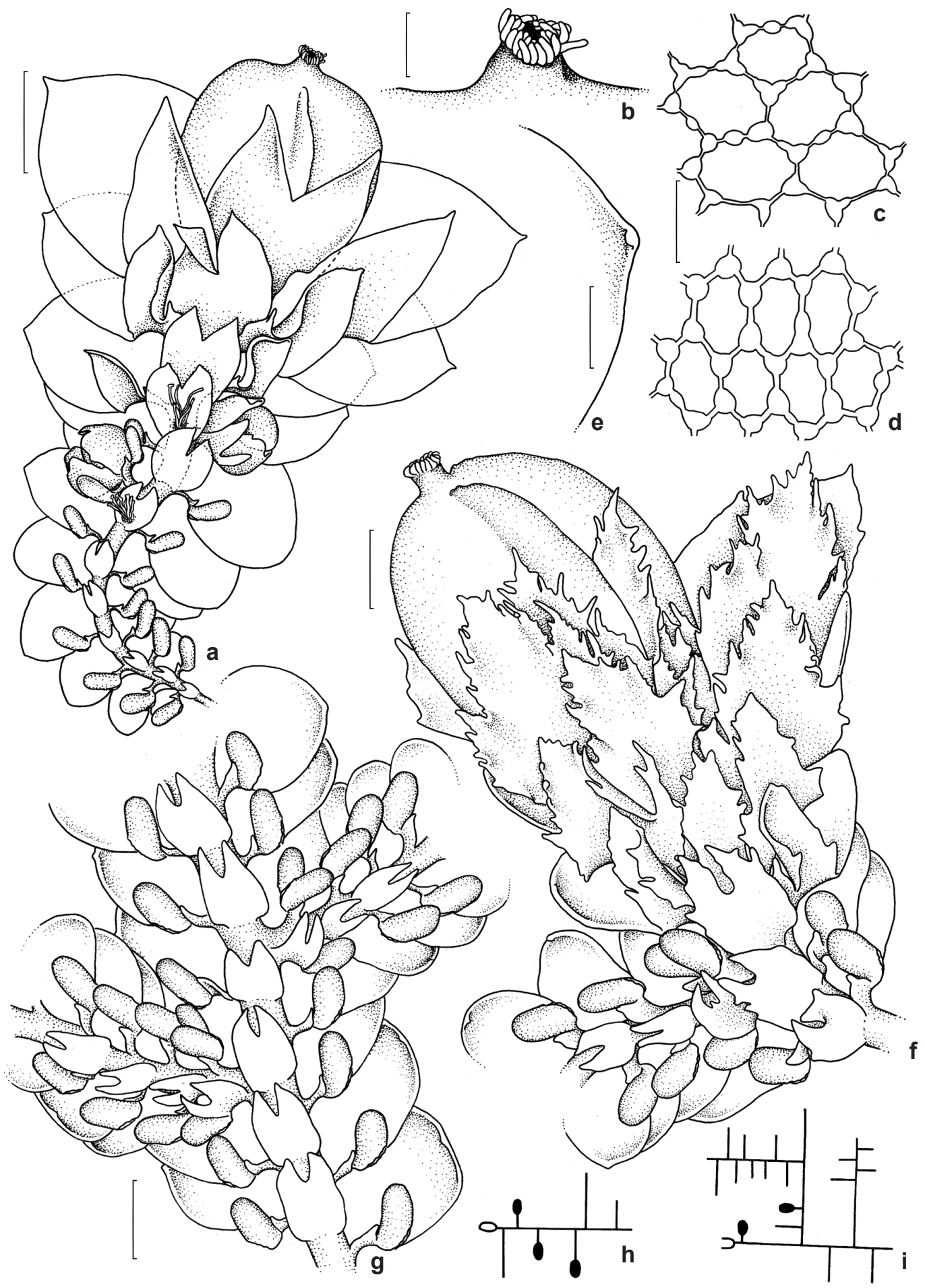

Figura 2 - a-i. Frullania exilis - a. hábito com perianto; b. rostro do perianto; c-d. células medianas; e. ápice de filídio; f. hábito com perianto; g. hábito; h. esquema de hábitos (esfera cheia $=$ androécio, esfera vazada $=$ ginoécio com perianto, $\mathrm{U}=$ ginoécio). Barras: $\mathrm{a}=500 \mu \mathrm{m} ; \mathrm{b}=100 \mu \mathrm{m} ; \mathrm{c}, \mathrm{d}=25 \mu \mathrm{m} ; \mathrm{e}=50 \mu \mathrm{m} ; \mathrm{e}=25 \mu \mathrm{m} ; \mathrm{f}=200 \mu \mathrm{m} ; \mathrm{g}=250 \mu \mathrm{m}$. Figure 2 - a-i. Frullania exilis - a. habit with perianth; b. perianth beak; c-d. median cells; e. leaf apex; f. habit with perianth; g. habit; h. habit scheme (dot= androecia, open dot= gynoecia with perianth, $\mathrm{U}=$ gynoecia). Bars: $\mathrm{a}=500 \mu \mathrm{m} ; \mathrm{b}=100 \mu \mathrm{m} ; \mathrm{c}, \mathrm{d}=25 \mu \mathrm{m} ; \mathrm{e}=50$ $\mu \mathrm{m} ; \mathrm{e}=25 \mu \mathrm{m} ; \mathrm{f}=200 \mu \mathrm{m} ; \mathrm{g}=250 \mu \mathrm{m}$. 
Material selecionado: Canaã dos Carajás, Serra Sul, S11C, 6²2'57,9"S, 5050²3'07'W, 29.IV.2015, A.L. Ilkiu-Borges et al. 3472 (MG); Serra do Tarzan, 6¹9'45”S, 5000'27,4”W, 758 m, 1.IX.2015, A.L. Ilkiu-Borges et al. 3652 (MG). Parauapebas, Serra Norte, N2, 603'19,4'S, 50¹5'17,7''W, 685 m, 31.VIII.2015, A.L. Ilkiu-Borges et al. 3609 (MG); N5, 602'36,4”S, $50^{\circ} 05^{\prime} 25,1$ 'W, 604 m, 2.IX.2015, A.L. Ilkiu-Borges et al. 3696 (MG); N6, 66'42,0”'S, 50¹1'01,9'”, 711 m, 24.II.2016, A.L. Ilkiu-Borges et al. 3756 (MG).

A espécie se caracteriza pelos lóbulos distantes do caulídio, com uma incisão no lado adaxial alcançando até a metade inferior do lóbulo, e filídios com ápice variando de arredondado a apiculado. Além disso, as células basais dos filídios de $F$. exilis podem se assemelhar a ocelos por serem pouco maiores e de cor mais intensa que as medianas, porém ocelos estão ausentes. Uma célula de cor mais intensa, como um ocelo, também está presente tanto no ápice da abertura (incisão) do lóbulo, como na junção do lóbulo com o estilete. Essas células são bem visíveis em microscópio ótico, principalmente em amostras recentes. Em F. exilis, as margens das brácteas e bractéolas femininas que podem variar de inteiras a serreadas, assim como o estilete varia (em uma planta) de lanceolado a filiforme partindo de uma base mais larga.

Essa espécie tem sido reportada no Brasil como Frullania apiculata (Reinw., Blume \& Nees) Nees, mas de acordo com Gradstein (2013), F. apiculata é uma espécie paleotrópica e todos os registros neotropicais dessa espécie (e.g., Gradstein \& Costa 2003; Gradstein \& Ilkiu-Borges 2009; Gradstein \& Uribe 2011) pertencem a F. exilis.

Frullania exilis é encontrada geralmente como corticícola em florestas tropicais, cerrado, restinga e outros ambientes abertos, de 200 a 3000 m de altitude (Gradstein \& Costa 2003; Gradstein \& Ilkiu-Borges 2009). Na Serra dos Carajás, a espécie foi coletada sobre troncos e galhos de árvores em canga aberta, mata baixa sobre canga e na margem de córrego temporário.

Neotropical. No Brasil: AM, PA, BA, PE, DF, GO, MS, RJ, SP e SC. Serra dos Carajás: Serra Norte: N2, N5 e N6; Serra Sul: S11C e Serra do Tarzan.

1.3. Frullania gibbosa Nees, Syn. Hepat. 3: 411, 1845.

Fig. $4 \mathrm{a}-\mathrm{i}$

Plantas autóicas, marrom-amareladas a verde-avermelhadas, 1-1,2 $\mathrm{mm}$ de largura, prostradas, fracamente aderida ao substrato, com ramos ascendentes, 1-2 pinados. Filídios firmes, ovalado-orbiculares, 950-1075 × 775-1000 $\mu \mathrm{m}$, \pm côncavo, plano, convolutos quando secos e esquarrosos quando úmidos, base dorsal auriculada (ultrapassando o caulídio), ápice arredondado, margem inteira. Células medianas isodiamétricas, 15-25 $\mu \mathrm{m}$, paredes regularmente espessadas, trigônios pequenos a inconspícuos, paredes regularmente espessadas (sem espessamentos intercelulares). Lóbulos contíguos ao caulídio, orbicular-galeados, 400-550 × 300-400 $\mu \mathrm{m}$, amplamente aderidos ao lobo (formando uma porção laminada), tão longos quanto largos, lóbulos laminares raros. Estilete foliado-arredondado. Anfigastros 1/9-1/5 bífidos, 3-4× largura do caulídio, suborbicular, 425-525 × 400-750 $\mu \mathrm{m}$, densamente imbricados, base auriculada, gibosa, margens inteiras, revoluta na parte superior. Brácteas e bractéolas do ginoécio com margens inteiras. Periantos oblongo, 1400-1500 × 800-1000 $\mu \mathrm{m}, 4$ quilhas, margens inteiras, superfície lisa, rostro curto, até $100 \mu \mathrm{m}$ comprimento.

Material selecionado: Canaã dos Carajás, Serra Sul, S11C, 6²2'57,9"S, 50²3'07'W, 29.IX.2015, A.L. Ilkiu-Borges et al. 3477 (MG); Serra do Tarzan, 6¹9'43,7'S, 5008'20,3"W, 31.IX.2015, A.L. IlkiuBorges et al. 3585 (MG). Parauapebas, Serra Norte, N1, 600'30,8"S, 50¹7'55,1'W, 679 m, 31.VIII.2015, A.L. Ilkiu-Borges et al. 3628 (MG); N7, 69'27,2”S, $50^{\circ} 10$ '15,2”W, 695 m, 24.II.2016, A.L. Ilkiu-Borges et al. 3784 (MG).

Frullania gibbosa assemelha-se a $F$. ericoides por serem espécies xerófitas, convolutas quando secas, esquarrosas quando úmidas e com lóbulos orbicular-galeados. Entretanto, F. gibbosa possui estilete folhoso-arredondado, filídios firmes, com lóbulos com porção laminar, anfigastros curtobífidos (1/9-1/5 bífidos) e perianto com quatro quilhas inteiras, enquanto que $F$. ericoides possui estilete filiforme, filídios frágeis, com lóbulo sem porção laminar, anfigastros $1 / 3$ bífido e perianto com três quilhas ciliadas a curto-laciniadas.

Essa espécie é uma especialista de sol, geralmente corticícola ou rupícola, que ocorre na copa de florestas ou outros ambientes abertos, como restinga, parques e jardins (Gradstein \& Costa 2003; Gradstein \& Ilkiu-Borges 2009). Nas cangas da Serra dos Carajás, F. gibbosa foi coletada sobre árvores vivas em mata baixa sobre canga, canga aberta ou às margens de córrego temporário e da lagoa de macrófitas.

América Tropical. No Brasil: AC, AM, BA, DF, GO, MG, MS, MT, PA, PE, RJ, RR, SC e SP. Serra dos Carajás: Serra Norte: N1 e N7; Serra Sul: S11C e Serra do Tarzan. 
1.4. Frullania intumescens (Lehm. \& Lindenb.) Lehm. \& Lindenb., Syn. Hepat. 3: 449, 1845.

Jungermannia intumescens Lehm. \& Lindenb., Nov. Stirp. Pug. 6: 52. 1834.

Fig. 5a-i

Plantas dióicas, marrons a marromesverdeadas, $1-1,2 \mathrm{~mm}$ de largura, prostradas, $1-3$ pinadas. Hemi-filídio inteiro (primeiro apêndice do ramo). Filídios firmes, ovalados, 580-700 × 490-570 $\mu \mathrm{m}$, fortemente côncavos, base dorsal auriculada (ultrapassando o caulídio), ápice obtuso a apiculado-mucronado, margem inteira. Células medianas isodiamétricas, $20-25 \mu \mathrm{m}$, trigônios radiados a inflados, geralmente confluentes, com paredes irregularmente espessadas, grupo de células basais similares a ocelos ausente. Lóbulos contíguos ao caulídio, subparalelos ao caulídio, curto-cilíndricos, 130-200 × 80-120 $\mu \mathrm{m}, \pm 2 \times$ mais longos que largos, sem incisão no lado adaxial (margens da abertura do lóbulo geralmente se estendendo abaixo da linha de inserção), lóbulos laminares frequentes. Estilete filiforme, 3-4 células comprimento, 1 de largura. Anfigastros 1/4 bífidos, 2-4× largura do caulídio, longo-ovalados, 300-400 × 190-360 $\mu \mathrm{m}$, subimbricados a imbricados, base arredondada a auriculada, margens fortemente revolutas. Brácteas e bractéolas do ginoécio com margens inteiras. Perianto obovado, $1300-1700 \times 650-1050 \mu \mathrm{m}$, 3 quilhas, margens inteiras, superfície lisa, rostro longo, 100-250 $\mu \mathrm{m}$ comprimento.

Material selecionado: Canaã dos Carajás, Serra Sul, S11B, 6021'19,1"S, 50²3'27,4”'W, 29.IX.2015, A.L. Ilkiu-Borges et al. 3519 (MG); S11C, 6²2'57,9"S, $50^{\circ} 23^{\prime} 07^{\prime \prime} \mathrm{W}$, 29.IX.2015, A.L. Ilkiu-Borges et al. 3476 (MG); Serra do Tarzan, $6^{\circ} 19^{\prime} 43,7^{\prime \prime S}, 50^{\circ} 08^{\prime} 20,3^{\prime \prime} \mathrm{W}$,
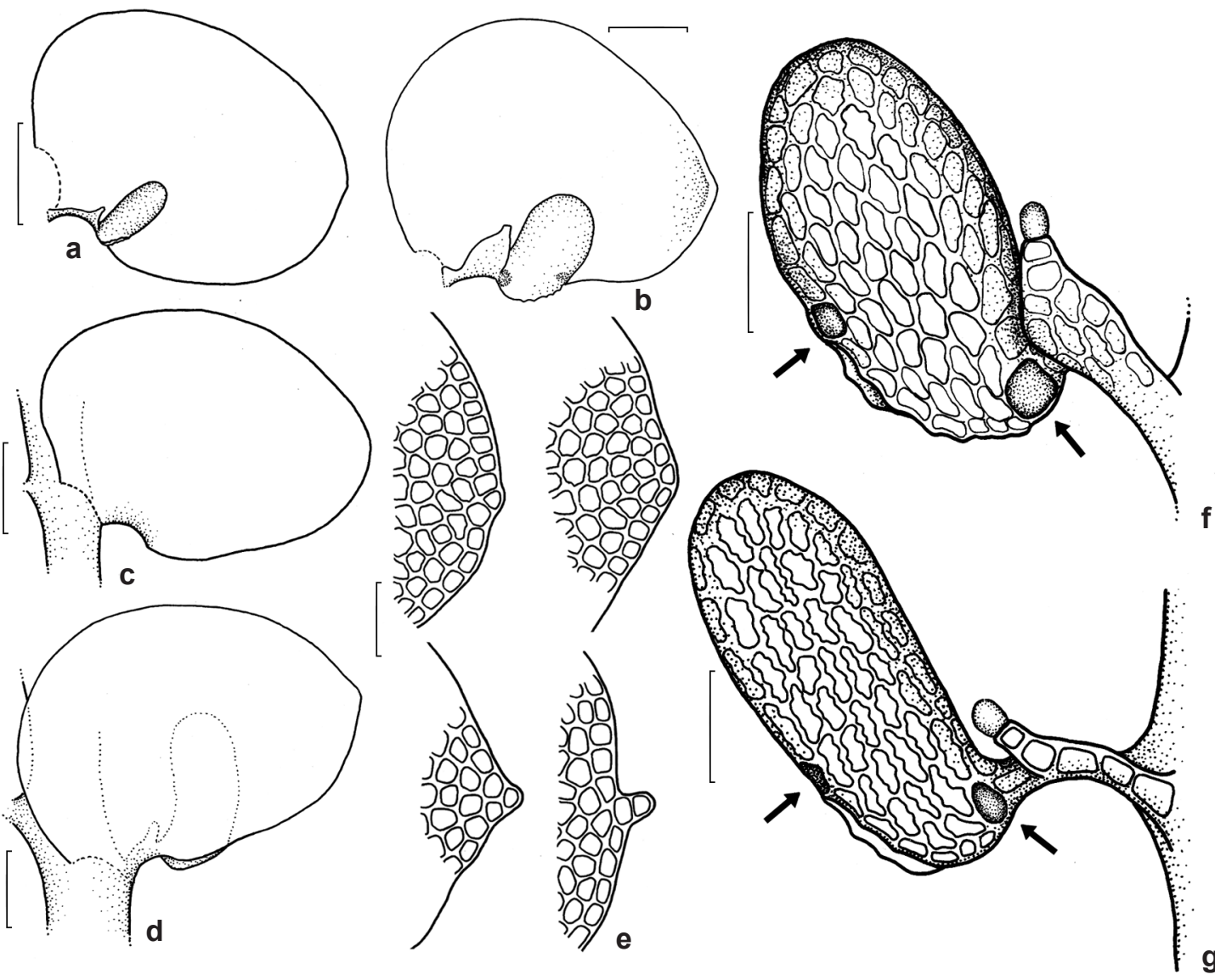

Figura 3 - a-g. Frullania exilis - a-b. filídio em vista ventral; c-d. filídio em vista dorsal; e. ápice de filídio; f-g. lóbulo com estilete. Barras: $\mathrm{a}, \mathrm{c}=250 \mu \mathrm{m} ; \mathrm{b}, \mathrm{d}=100 \mu \mathrm{m}$; e, $\mathrm{f}, \mathrm{g}=50 \mu \mathrm{m}$.

Figure 3 - a-g. Frullania exilis - a-b. leaf in ventral view; c-d. leaf in dorsal view; e. leaf apex; f-g. lobule with style. Bars: a, c=250 $\mu \mathrm{m} ; \mathrm{b}, \mathrm{d}=100 \mu \mathrm{m} ; \mathrm{e}, \mathrm{f}, \mathrm{g}=50 \mu \mathrm{m}$. 
31.IX.2015, A.L. Ilkiu-Borges et al. 3586 (MG). Parauapebas, Serra Norte, N1, 601'32,3'S, 50¹7'32,5'W, 719 m, 28.IV.2015, A.L. Ilkiu-Borges et al. 3437 (MG); N2, 603'20,1'S, 50¹5'14,9'”, 685 m, 28.IV.2015, A.L. Ilkiu-Borges et al. 3429 (MG); N4, 604'18'"S, 50¹1'39,2'W, 617 m, 03.IX.2015, A.L. Ilkiu-Borges et al. 3710 (MG); N5, 602'36,4”'S, 5005'25,1'W, 604 m, 2.IX.2015, A.L. Ilkiu-Borges et al. 3696 (MG); N6, 66'42,0'S, 50¹1'01,9'”, 711 m, 24.II.2016, A.L. IlkiuBorges et al. 3750 (MG); N7, 69'27,2”S, 50¹0'15,2”W, 695 m, 24.II.2016, A.L. Ilkiu-Borges et al. 3769 (MG) ; N8, 6¹0'00,6”S, 5009'34,1'W, 716 m, 24.II.2016, A.L. Ilkiu-Borges et al. 3802 (MG).
As características marcantes desta espécie são os lóbulos curto-cilíndricos, contíguos e paralelos ao caulídio, sem abertura incisa, anfigastros bífidos com margem revoluta e base arredondada a auriculada, hemi-filídio inteiro, filídios côncavos com ápice geralmente apiculado e incurvado e base dorsal auriculada, ultrapassando o caulídio, e o longo rostro do perianto. Nas cangas de Carajás, as brácteas e bractéolas femininas dessa espécie apresentaram margens inteiras, mas essas podem variar de inteiras, sinuosas a denteadas em $F$. intumescens (Clark \& Svihla 1952).

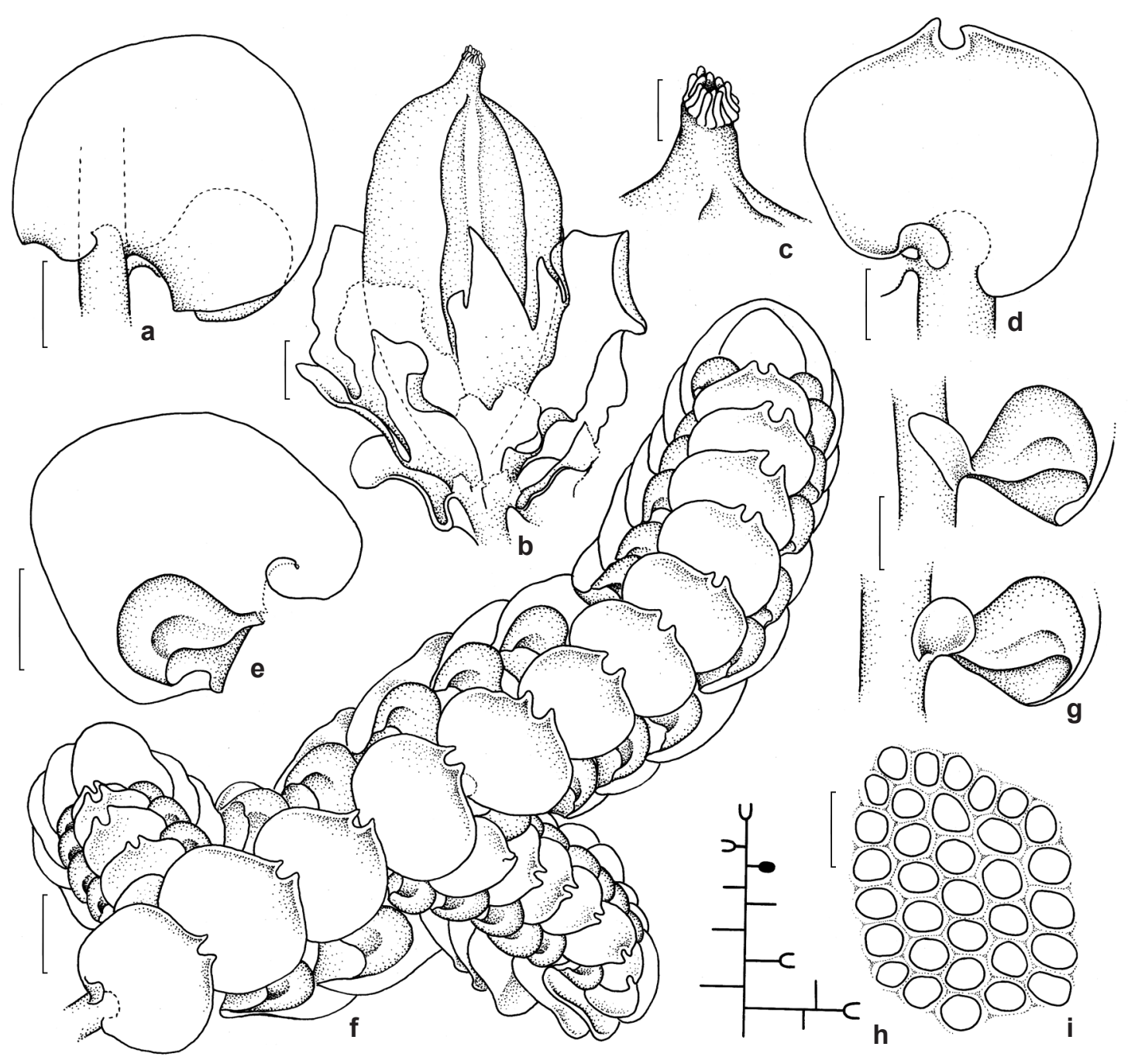

Figura 4 - a-i. Frullania gibbosa - a. filídio em vista dorsal; b. ginoécio com perianto; c. rostro do perianto; d. anfigastro; e. filídio; f. hábito; g. lóbulo com estilete; h. esquema de hábitos (esfera cheia= androécio, esfera vazada= ginoécio com perianto, $\mathrm{U}=$ ginoécio); i. células medianas. Barras: a, b, d, e, $g=250 \mu \mathrm{m} ; \mathrm{c}=100 \mu \mathrm{m} ; \mathrm{f}=500 \mathrm{~m} ; \mathrm{i}=50 \mu \mathrm{m}$.

Figure 4 - a-i. Frullania gibbosa - a. leaf in dorsal view; b. gynoecia with perianth; c. perianth beak; d. underleaf; e. leaf; f. habit; g. lobule with style; h. habit scheme (dot= androecia, open dot= gynoecia with perianth, $\mathrm{U}=$ gynoecia); i. median cells. Bars: a, b, d, e, $g$ $=250 \mu \mathrm{m} ; \mathrm{c}=100 \mu \mathrm{m} ; \mathrm{f}=500 \mathrm{~m} ; \mathrm{i}=50 \mu \mathrm{m}$. 
Frullania intumescens às vezes produz um apêndice foliar no estilete (Gradstein \& Uribe 2011), porém esse apêndice não foi encontrado nos espécimes das cangas de Carajás. O mesmo fenótipo já foi reportado por Gradstein \& Uribe (2011) para a Colombia e por Schäfer-Verwimp et al. (2013) para o Equador.

É uma espécie corticícola ou rupícola que ocorre entre 500 e $1000 \mathrm{~m}$ de altitude (Gradstein \&
Costa 2003). Nas Serra dos Carajás, F. intumescens ocorreu sobre tronco de árvores vivas e troncos em decomposição em mata baixa sobre canga, canga aberta, campos brejosos, a margens de lagos e de córrego temporário. Este é o primeiro registro para o estado do Pará e região Norte.

América Tropical. No Brasil: MG e RJ. Serra dos Carajás: Serra Norte: N1, N2, N4, N5, N6, N7 e N8; Serra Sul: S11B, S11C e Serra do Tarzan.

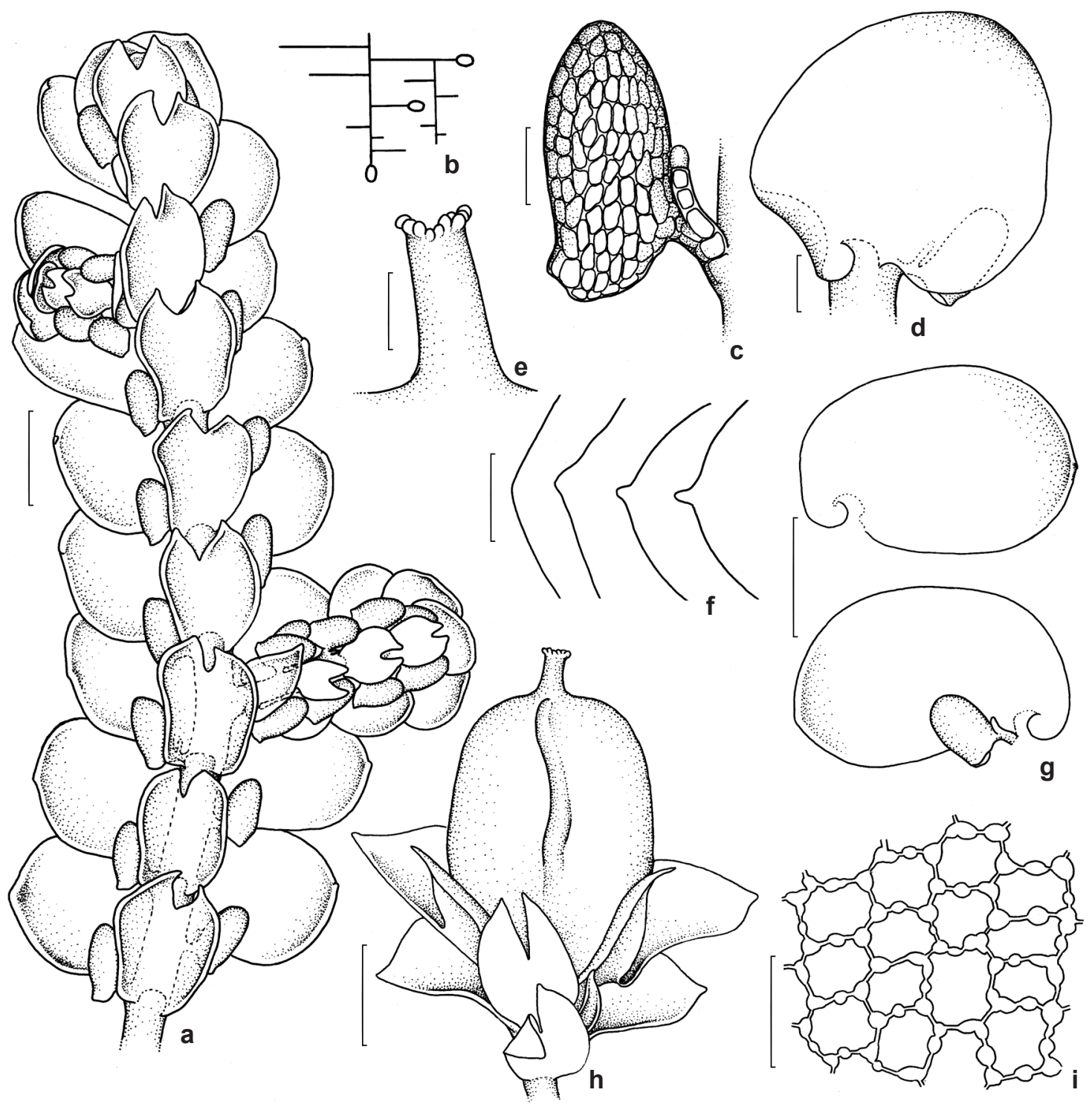

Figura 5 - a-i. Frullania intumescens - a. hábito; b. esquema de hábitos (esfera vazada= ginoécio com perianto); c. lóbulo com estilete; d. filídio em vista dorsal; e. rostro do perianto; f. ápice de filídios; g. filídios; h. ginoécio com perianto; i. células medianas. Barras: $\mathrm{a}, \mathrm{g}=250 \mu \mathrm{m} ; \mathrm{c}, \mathrm{h}=50 \mu \mathrm{m} ; \mathrm{d}, \mathrm{e}, \mathrm{f}=100 \mathrm{~m} ; \mathrm{h}=500 \mu \mathrm{m} ; \mathrm{i}=25 \mu \mathrm{m}$.

Figure 5 - a-i. Frullania intumescens - a. habit; b. habit scheme (open dot= gynoecia with perianth); c. lobule with style; $d$. leaf in dorsal view; e. perianth beak; f. leaf apex; g. leaves; h. gynoecia with perianth; i. median cells. Bars: a, g = 250 $\mu \mathrm{m} ; \mathrm{c}, \mathrm{h}=50 \mu \mathrm{m} ; \mathrm{d}$, e, $\mathrm{f}=100 \mathrm{~m} ; \mathrm{h}=500 \mu \mathrm{m} ; \mathrm{i}=25 \mu \mathrm{m}$. 


\section{Agradecimentos}

Agradecemos ao Museu Paraense Emílio Goeldi e Instituto Tecnológico Vale, a infraestrutura e demais apoios fundamentais para o desenvolvimento deste trabalho, assim como à Dra. Ana Maria Giulietti Harley e ao Dr. Pedro Viana, coordenadores do projeto conveniado MPEG/ITV/FADESP (01205.000250/2014-10) e ao projeto aprovado pelo CNPq (processo 455505/2014-4), o financiamento; ao ICMBio, em especial ao biólogo Frederico Drumond Martins, a licença de coleta concedida e suporte nos trabalhos de campo; ao Prof. Dr. S. Robbert Gradstein (Herbier de Paris, MNHN), os comentários no manuscrito e auxílio no reconhecimento das espécies; ao CNPq e Programa de Pós-graduação em Ciências Biológicas - Botânica Tropical (UFRA/MPEG), a bolsa de Mestrado concedida a primeira autora e ao segundo autor e a bolsa de Produtividade em Pesquisa concedida à terceira autora.

\section{Referências}

Clark L \& Svihla RD (1952) Frullania intumescens. The Bryologist 55: 186-189.

Costa DP \& Peralta DF (2015) Bryophytes diversity in Brazil. Rodriguésia 66: 1063-1071.

Gradstein SR (2013) Afro-American hepatics revisited. Polish Botanical Journal 58: 149-177.

Gradstein SR \& Costa DP (2003) The Hepaticae and Anthocerotae of Brazil. Memoirs of The New York Botanical Garden 87: 1-318.

Gradstein SR \& Ilkiu-Borges AL (2009) Guide to the Plants of Central French Guiana. Part 4. Liverworts and Hornworts. Memoirs of The New York Botanical Garden 76: 1-140.

Gradstein SR \& Uribe-M J (2011) A synopsis of the Frullaniaceae (Marchantiophyta) from Colombia. Caldasia 33: 367-396.

Gradstein SR, Churchill SP \& Salazar-Allen N (2001) Guide to the Bryophytes of tropical America. Memoirs of the New York Botanical Garden 86: 1-577.
Heinrichs J, Reiner-Drehwald ME, Feldberg K, Grimaldi DA, Nascimbene PC, von Konrat M \& Schmidt AR (2011) Kaolakia borealis nov . genetsp (Porellales, Jungermanniopsida): a leafy liverwort from the Cretaceous of Alaska. Review of Palaeobotany and Palynology 165: 235-240.

Heinrichs J, Feldberg K, Bechteler J, Müller P, Renner MAM, Váňa J, Schäfer-Verwimp A \& Schmidt AR (2017) A fossil genus of the Frullaniaceae (Porellales,Jungermanniopsida) from the midCretaceous of Myanmar. Cretaceous Research 74: 223-226.

Schäfer-Verwimp A, Lehnert M \& Nebel M (2013) Contributions to the knowledge of the bryophyte flora of Ecuador. Phytotaxa 128: 1-63.

Schuster RM (1992) Hepaticae and Anthocerotae of North America east of the hundredth meridian. Vol. 5. Field Museum of Natural History, Chicago. Pp. 1-854.

Silva SE, Silva DN, Almeida T, Garcia CA, Paulo OS \& Sim-Sim M (2016) Age estimates of Frullania (Frullaniaceae, Porellales) main lineages: another example of rapid and recent diversification in liverwort evolution, Systematics and Biodiversity. 15: 156-165.

Söderström L, Hagborg A, von Konrat M, BartholomewBegan S, Bell D, Briscoe L, Brown E, Cargill DC, Costa DP, Crandall-Stotler BJ, Cooper ED, Dauphin G, Engel JJ, Feldberg K, Glenny D, Gradstein SR, He X-L, Heinrichs J, Hentschel J, Ilkiu-Borges AL, Katagiri T, Konstantinova NA, Larraín J, Long DG, Nebel M, Pócs M, Puche F, Reiner-Drehwald E, Renner MAM, Sass-Gyarmati A, Schäfer-Verwimp A, Moragues JGS, Stotler RE, Sukkharak P, Thiers BM, Uribe J, Váňa J, Villarreal JC, Wigginton M, Zhang L \& Zhu R-L (2016) World Checklist of hornworts and liverworts. Phytokeys 59: 1-828.

Vanden Berghen C (1976) Frullaniaceae (Hépaticae) Africanae. Bulletin du Jardin Botanique National de Belgique 46: 1-220.

Wigginton MJ (ed.) (2004) E.W. Jones's Liverwort and hornwort flora of West Africa. Meise, National Botanic Gerden of Belgium. 443p.

\section{Lista de exsicatas}

Ilkiu-Borges AL et al. 3678 (1.1), 3472 (1.2, 1.4), 3473 (1.2), 3609 (1.2), 3610 (1.2), 3652 (1.2), 3696 (1.2), 3697 (1.2), 3736 (1.2), 3737 (1.2), 3742 (1.2), 3745 (1.2), 3746 (1.2), 3756 (1.2), 3477 (1.3), 3480 (1.3), 3585 (1.3), 3628 (1.3), 3635 (1.3), 3637 (1.3), 3784 (1.3), 3790 (1.3), 3796 (1.3), 3586 (1.4), 3430 (1.4), 3434 (1.4), 3437 (1.4), 3451 (1.4), 3477 (1.4), 3480 (1.4), $3483(1.4), 3488$ (1.4), $3494(1.4), 3498$ (1.4), 3626 (1.4), 3633 (1.4), 3711 (1.4), 3775 (1.4), 3783 (1.4), 3790 (1.4), 3433 (1.4), $3436(1.4), 3441$ (1.4), 3449 (1.4), 3450 (1.4), 3484 (1.4), 3504 (1.4), 3511 (1.4), 3519 (1.4), 3600 (1.4), 3604 (1.4), 3611 (1.4), 3623 (1.4), 3624 (1.4), 3634 (1.4), 3652 (1.4), 3664 (1.4), 3696 (1.4), 3702 (1.4), 3706 (1.4), 3718 (1.4), 3794 (1.4), 3795 (1.4), 3796 (1.4), 3797 (1.4), 3798 (1.4), 3800 (1.4), 3802 (1.4). 
